\title{
Asthma and COVID-19: Emphasis on Adequate Asthma Control
}

\author{
David D. Nassoro $\mathbb{D}^{1,2}$ Leodegard Mujwahuzi, ${ }^{1,2}$ Issakwisa Habakkuk Mwakyula $\mathbb{D}^{1,2}$ \\ Mwajabu K. Possi, ${ }^{3}$ and Sylvester L. Lyantagaye ${ }^{4}$ \\ ${ }^{1}$ Department of Internal Medicine, University of Dar Es Salaam, Mbeya College of Health and Allied Sciences, \\ Mbeya, Tanzania \\ ${ }^{2}$ Department of Internal Medicine, Mbeya Zonal Referral Hospital, Mbeya, Tanzania \\ ${ }^{3}$ Department of Social Sciences, University of Dar Es Salaam, Mbeya College of Health and Allied Sciences, Mbeya, Tanzania \\ ${ }^{4}$ Department of Biochemistry and Molecular Biology, University of Dar Es Salaam, Mbeya College of Health and Allied Sciences, \\ Mbeya, Tanzania
}

Correspondence should be addressed to David D. Nassoro; ares39@gmail.com

Received 13 April 2021; Revised 18 July 2021; Accepted 13 August 2021; Published 27 August 2021

Academic Editor: Dejan Radovanovic

Copyright (C) 2021 David D. Nassoro et al. This is an open access article distributed under the Creative Commons Attribution License, which permits unrestricted use, distribution, and reproduction in any medium, provided the original work is properly cited.

\begin{abstract}
Asthmatics are at an increased risk of developing exacerbations after being infected by respiratory viruses such as influenza virus, parainfluenza virus, and human and severe acute respiratory syndrome coronaviruses (SARS-CoV). Asthma, especially when poorly controlled, is an independent risk factor for developing pneumonia. A subset of asthmatics can have significant defects in their innate, humoral, and cell-mediated immunity arms, which may explain the increased susceptibility to infections. Adequate asthma control is associated with a significant decrease in episodes of exacerbation. Because of their wide availability and potency to promote adequate asthma control, glucocorticoids, especially inhaled ones, are the cornerstone of asthma management. The current COVID-19 pandemic affects millions of people worldwide and possesses mortality several times that of seasonal influenza; therefore, it is necessary to revisit this subject. The pathogenesis of SARS-CoV-2, the virus that causes COVID-19, can potentiate the development of acute asthmatic exacerbation with the potential to worsen the state of chronic airway inflammation. The relationship is evident from several studies that show asthmatics experiencing a more adverse clinical course of SARS-CoV-2 infection than nonasthmatics. Recent studies show that dexamethasone, a potent glucocorticoid, and other inhaled corticosteroids significantly reduce morbidity and mortality among hospitalized COVID-19 patients. Hence, while we are waiting for more studies with higher level of evidence that further narrate the association between COVID-19 and asthma, we advise clinicians to try to achieve adequate disease control in asthmatics as it may reduce incidences and severity of exacerbations especially from SARS-CoV-2 infection.
\end{abstract}

\section{Introduction}

Asthma is a significant, independent risk factor for developing lower respiratory tract infection [1-4], including viral pneumonia [5-8]. The observed increased incidence is generally due to relative immune dysfunction against various etiologies observed in asthmatics [9-11]. Asthma exacerbations are commonly seen in the pediatric population; however, they can also occur in adults and are precipitated mainly by viral infections [12]. Despite rhinovirus being the commonest infectious etiology for asthma exacerbation, virtually all other respiratory viruses can cause exacerbations [13]. In addition, bacterial etiologies can also significantly contribute to worsening asthma control, as shown in one meta-analysis study that concluded that asthma is a significant risk factor for developing invasive pneumococcal disease [14]. Thus, reducing exacerbation triggers is one of the most critical variables in achieving disease control, and currently, it is the main target in the management of asthma [15].

According to the recent Global Initiative for Asthma (GINA) update, asthma is a heterogeneous disease, usually characterized by chronic airway inflammation [16]. An 
asthma diagnosis is generally reached after a patient presents with respiratory symptoms such as wheeze, shortness of breath, chest tightness, and cough that vary over time and intensity, with variable expiratory airflow limitation that reverses upon using $\beta_{2}$ adrenergic agonist [16]. According to the $\mathrm{WHO}$, in 2019, the prevalence of asthmatics worldwide was 262 million, and, in that year alone, asthma contributed to 461,000 deaths [17].

Some countries have succeeded in reducing asthma exacerbation and hospitalization; however, in developing countries, the adverse clinical outcomes have increased by more than $30 \%$ in the past 20 years $[18,19]$. The negative impact of asthma is widely felt by patients and relatives and by society and the healthcare system. Patients with persistent disease tend to experience more episodes of exacerbations, including recurrent pneumonia, compared with patients who are well controlled [20-23].

At the end of 2019, a novel coronavirus was implicated as an etiology of a cluster of pneumonia cases in Wuhan, Hubei Province in China. In February 2020, the World Health Organization (WHO) coined the disease caused by severe acute coronavirus 2 (SARS-CoV-2) coronavirus disease 2019 (COVID-19) [24]. It spread rapidly at an alarming rate throughout the world. In mid-march of 2020, the WHO recognized the illness as pandemic $[25,26]$. The disease's symptomatic presentation varied widely; however, the primary clinical manifestation is mainly confined within the respiratory system with variable systemic responses depending on severity. The majority of symptomatic cases are due to pneumonia, while critical cases are mainly due to immune hyperactivation leading to cytokine storm [27-31].

Some of the risk factors for severe disease and death are older age, cardiovascular disease, diabetes mellitus, chronic respiratory diseases, hypertension, and cancer [32]. In one of the initial epidemiological studies to elucidate the risk factors for mortality in patients with COVID-19 in New York in 2020, asthma was not shown to be an independent risk factor for hospitalization; however, chronic obstructive pulmonary disease was significantly associated with mortality [33]. Furthermore, a recent GINA update on asthma and COVID-19 concluded that according to currently available evidence, asthmatics do not appear to be at an increased risk of acquiring COVID-19, and well-controlled and mild to moderate asthmatics did not appear to be at an increased risk of severe COVID-19; however, the risk for mortality was increased in asthmatics who recently needed inhaled corticosteroids and hospitalized patients with severe asthma [34, 35]. Additionally, in early 2020, The United States CDC advised asthmatic patients with moderate to severe illness to take extra measures to protect themselves as there is a risk of severe manifestation of COVID-19 [32].

A 2004 GINA survey found that the prevalence of asthmatics worldwide was 300 million, and it is expected to rise to more than 400 million by 2025 [36]. The prevalence of asthma varies from one region to another, and it is highly dependent on socioeconomic factors, wherein developing countries, health-seeking behavior and asthma case identification are poor [37]. Especially in developing countries, asthma is underdiagnosed and inadequately managed, leading to a higher prevalence of asthmatics who are poorly controlled $[38,39]$. In developed countries, the prevalence of asthma ranges from $7 \%$ of the total population in France to around $15 \%-18 \%$ in the United States [40]. A systematic analysis that estimated the prevalence of asthma in Africa found that by 2010, 12.8\% of Africans had asthma [38]. However, for the reasons discussed above, the prevalence in Africa may be significantly higher because of various reasons leading to underdiagnosis. A 2006 to 2008 behavioral risk factor surveillance system conducted by the CDC found that almost $64 \%$ of asthmatics in the United States had a persistent disease [41]. Furthermore, evidence during the early days of COVID-19 showed that asthmatics are overrepresented among hospitalized COVID-19 patients [35, 42, 43]. Asthma exacerbations are primarily due to poor disease control; therefore, due to the overwhelming burden of poorly controlled asthmatics globally, it is essential to revisit this topic, especially when we are facedwith a virulent respiratory virus pandemic[44-47].

\section{Asthma Disease Control and Risk of Exacerbation}

The accepted definition of asthma control and severity is arbitrary. However, a joint task force of the American Thoracic Society (ATS) and European Respiratory Society (ERS) manage to propose definitions of the terms. According to the task force, asthma severity is defined as the difficulty in controlling asthma with treatment after excluding modifiable factors such as poor adherence, smoking, and comorbidities. Severity primarily reflects the required level of treatment and the underlying disease state's activity during treatment. At the same time, asthma control encompasses not only the patient's current clinical state (symptoms, night waking, reliever use, and lung function) but also considers their "future risk" - that is, their potential for experiencing adverse outcomes, such as loss of control in the near or distant future, exacerbations, accelerated decline in lung function, or treatment-related side effects. It is emphasized that even if current poor control predicts future poor control and healthcare utilization, other pathologic and physiologic measures, independent of the level of current clinical control, can influence future risk [48].

The above definitions are relatively more practical in day-to-day practice; however, GINA came with a rather exhaustive list of variables to approach the meaning of control [49]. Thus, asthma is considered controlled if all of these features were present: diurnal symptoms less than once a week and no asthma attacks in the last three months, no activity (work or other activities) limitations in the last 12 months, no nocturnal symptoms in the last three months, short-acting $\beta_{2}$ agonist twice or less per week in the last three months and no use of oral steroids in the last 12 months, and forced expiratory volume in one second $\left(\mathrm{FEV}_{1}\right)$ of $80 \%$ of predicted value or greater. Moreover, asthma is considered partly controlled if one or two of the above features were absent and uncontrolled if more than two features were absent or if asthma, shortness of breath, or wheezing had caused hospital/ 
emergency department admissions in the last 12 months; oral steroids were used in short courses of continuously in the last 12 months; or the subject had more than 12 attacks ( 1 per week or more) in the last three months.

In a large surveillance study done in the United States from 2006 to 2010, the Behavioral Risk Factor Surveillance System (BRFSS) that surveilled almost 10,000 and 52,000 children and adults with asthma, respectively, found that more than $38 \%$ of asthmatic children and $50 \%$ of asthmatic adults were uncontrolled [50]. Furthermore, a large surveillance study done in 10 countries in Europe found that $49 \%$ of adult asthmatics were poorly controlled [49]. In Asia, a large cross-sectional survey study found that more than $50 \%$ of patients experienced daytime symptoms; however, the information on the extent of disease control in the study was lacking [39]. Data estimating the extent of disease control in other regions containing developing countries is scarce; however, we can extrapolate asthma control in patients who reside in a region like Africa; specifically, subSaharan Africa will be poor, probably worse than in developed countries; this may be because of various challenges such as underdiagnosis of childhood asthma, inadequate asthma management, poor access to care, poor availability and relative prohibitive cost of inhaled medications, impaired control of environmental and potential triggers, inadequate disease education from healthcare providers, cultural and language barriers [51].

Asthma control is preferred instead of grading severity because several cross-sectional surveys from various countries have shown that the use of either inhaled corticosteroids (ICS) or rapid-acting reliever medications is independent of asthma severity [39, 52]. For example, a European survey of patients with persistent asthma symptoms showed that ICS were used by only $25 \%$ of adults with severe asthma, 23\% with moderate asthma, and 28\% with mild asthma. For children, the corresponding figures were $26 \%, 33 \%$, and 33\%, respectively [52]. Similar findings were recorded in a study of 3207 patients in Asia who participated in the Asthma Insight and Reality in Asia-Pacific (AIRAP) study [39].

Asthma exacerbation is one of the predictors of poorly controlled asthma; however, it cannot define it. Several factors can predict asthma exacerbations; some are pediatric patients, lower socioeconomic status, poor day-today asthma control, and active airway inflammation, especially if it is refractory to inhaled steroids [53]. However, respiratory infections, especially viral, are implicated in more than $80 \%$ of exacerbations, with rhinovirus (RV) infections responsible for more than $66 \%$ of cases [54,55]. Lower respiratory tract symptoms, decreased lung function, and bronchial hyper-responsiveness are more prevalent in asthmatics with rhinovirus infection than in controls, and viral load correlates positively with the severity of symptoms [56]. Pathogenesis of rhinovirus is similar to SARS-CoV-2; however, the extent of inflammation due to COVID-19 is significantly more profound. Similar to COVID-19, RV induces inflammation where inflammatory cells such as neutrophil, eosinophil, CD4+ and CD8+, lymphocytes and mast cells are either activated or attracted to the area of infection in the airway parenchyma. Furthermore, there is an increase in the production of cytokines such as IL-6, IL-8, IL-16, INF- $\alpha$, and interferon-gamma-induced protein 10 (IP-10) [57]. These proinflammatory cytokines can lead to airway hyper-responsiveness, inflammation, and increased mucus secretion [58].

\section{Glucocorticoids as an Essential Drug for Asthma Disease Control}

Several drugs are used for asthma control; however, in recent times, ICS have been the drugs of choice principally by reducing inflammation and increasing tolerance to triggers, especially in allergic asthma than nonallergic asthma $[59,60]$. Additionally, several studies have shown that they are critical in achieving disease control in asthmatics [61-63]. ICS, even though not all patients may have access to obtain them, especially in developing countries, are widely available in many parts of the world [64]. The first ICS was beclomethasone dipropionate introduced in the early 1970 s and was a revolutionary therapy in controlling asthma exacerbation while causing few adverse events compared with systemic glucocorticoids commonly used at the time [65]. By far, ICS are the most effective therapy used as controllers in asthmatics, and their use is recommended by reputable guidelines worldwide $[61,66,67]$. Some of the commonly used ICS are budesonide, beclomethasone, and fluticasone [68].

Pharmacological effects of glucocorticoids result from gene expression from binding the glucocorticoid receptor (GR), a member of the superfamily of nuclear receptors in the cytoplasm. Therefore, the overall outcome is either the promotion or inhibition of transcription of the respective genes [69]. Different mechanisms that were previously used to assess the potency of glucocorticoids did not account for the target organ difference in potency, and the suppressive effect on the adrenal gland may not necessarily reflect the anti-inflammatory action [70]. Therefore, it was essential to rank the ICS' potency based on their anti-inflammatory actions in the lungs; one study that assessed transactivation and transrepression of respiratory mediators came with the rank order that shows fluticasone propionate $>$ budesonide $>$ beclomethasone dipropionate, triamcinolone acetonide, and flunisolide [71]. ICS have broad antiinflammatory effects in asthmatics and are effective in many patients with persistent asthma $[72,73]$. Hence, ICS function mainly by reducing asthma symptoms, improving peak expiratory flow rate and quality of life. Furthermore, they diminish airway hyper-responsiveness and prevent or reduce the frequency of exacerbations [74].

Several studies have shown that ICS in asthmatics and COPD patients can increase the risk of upper respiratory tract infection and pneumonia [75-77]. In vitro studies have proposed that ICS may impair innate immune responses and reduce viral clearance [78-80]. The above observationsare not universal as other studies did not find an association between ICS and high incidence of pneumonia in asthmatics 
$[81,82]$. Therefore, they underpin the fact that the use of corticosteroids, especially in viral infections, is still debatable and should be individualized based on the viral etiology in question and the stage or severity of the disease.

\section{Glucocorticoids and COVID-19}

Even before the emergence of SARS-CoV-2 in late 2019, there exists evidence to suggest the added benefit of using corticosteroids in viral infections, specifically those due to coronaviruses. An early study found that pretreatment of human respiratory cells in vitro with budesonide, combined with glycopyrronium and formoterol, inhibited human coronavirus's (HCoV-229E) replication capacity and was associated with the reduction of cytokine production [83]. Recently, preliminary studies that used intravenous hydrocortisone or dexamethasone in patients with moderate to severe COVID-19 were halted early after the data suggested statistical, clinical benefit $[84,85]$. In a large clinical trial, the RECOVERY trial, published in early 2021, 2104 and 4321 hospitalized patients with COVID-19 were assigned to receive either oral or intravenous dexamethasone $6 \mathrm{mg}$ once daily for up to 10 days or usual care. 482 patients $(22.9 \%)$ in the dexamethasone group and 1110 patients $(25.7 \%)$ in the usual care group died within 28 days after randomization (age-AOR $=0.83 ; 95 \%$ CI $[0.75-0.93] ; P<0.001$ ) [86]. With these findings, the study recommended dexamethasone for treating patients with COVID-19 who are on supplemental oxygen, and if unavailable, other corticosteroid equivalents, such as hydrocortisone, methylprednisolone, and prednisolone, may be used [87].

A significant randomized controlled trial published in early 2021 that assessed the clinical outcomes of hospitalized patients with COVID-19 in the aspect of the use of ICS in asthmatics and COPD patients in the United Kingdom showed that in patients 50 years and older, ICS use in asthmatics was associated with lower mortality than in those patients without an underlying respiratory condition [34]. Furthermore, in a similar randomized controlled trial where all adults irrespective of asthma diagnosis were initiated on either inhaled budesonide or placebo within seven days from the onset of mild COVID-19 symptoms in addition to conventional treatment, primary outcomes of COVID-19related urgent care visit or hospitalization were reduced to $3 \%$ in the ICS group as opposed to $15 \%$ in the conventional treatment group [88]. Therefore, these findings suggest that besides playing a significant part in achieving adequate asthma control, ICS use in asthmatics may be crucial in reducing adverse clinical outcomes following COVID-19 diagnosis. Some of the important studies that analyzed the importance of steroids in SARS-CoV-2 infection are summarized in Table 1.

\section{The State of Relative Immune Dysfunction in Asthmatics}

Most of the research done in asthmatics is directed toward explaining the causes, prognosis, and therapy, while few studies have been done that show the pathogenesis of asthma as one of the significant risk factors of pneumonia. One of the mechanisms of immune dysfunction may be the increased risk of infection due to opportunistic pathogens secondary to airway inflammation in patients whose disease is poorly controlled. In a proportion of asthmatics, dysfunction of innate, humoral, and cell-mediated immunity (CMI) has been an essential contributing factor for the observed increased incidence of microbial infections, especially in the respiratory system.

Innate immune dysfunction and impaired T-helper type 2 (Th2) response at the level of epithelial cells can occur in patients with asthma $[56,89,90]$. The discovered mechanism is pertinent to the increased risk of viral infections by the impaired secretion of interferon beta (INF- $\beta$ ) and INF- $\lambda$ by bronchial epithelial cells and bacterial infection by the impairment of toll-like receptor 2-mediated signal transduction recruiting neutrophils in atopic patients [9, 91, 92]. Additionally, several studies have found evidence of impairment of humoral immune response in patients with atopic conditions such as asthma that contribute to an increase in susceptibility to microbial infection and their overall progression and adverse clinical outcomes. For example, an early randomized control study that assessed the response of asthmatic and control subjects to tetanus toxoid found that 13 of 74 asthmatic patients (18\%) and 1 of 74 controls $(1.3 \%)$ had no response $(P<0.001)$ [93]. Another study conducted in patients with atopic dermatitis yielded similar results [94]. Moreover, a study comparing antibody levels of pneumococcal vaccine (PPV-23) in children aged 2 to 18 years found that patients with asthma had significantly lower antibody levels than children without asthma both before and after vaccination [95].

Additionally, cell-mediated immunity (CMI) in a subset of asthmatics can be impaired. The exact mechanism of impairment of CMI in this patient population is still poorly understood. One of the early studies to show the dysfunction of CMI in asthmatics was done by Grove et al. and reported that $9.2 \%$ and $1.2 \%$ of asthmatics and controls, respectively, had no delayed-type hypersensitivity response to any of fungal, viral, and tuberculous antigens $(P<0.02)$ [93]. Similar findings were found in patients with atopic [94]. In Japan, a study found an inverse relationship between the delayed hypersensitivity reaction to Mycobacterium tuberculosis and atopy [96]. Furthermore, patients with atopic dermatitis complicated with herpes simplex virus (HSV) infection had significantly fewer INF- $\gamma$ spot forming cells and less secretion of INF- $\gamma$ by peripheral blood mononuclear cells stimulation by HSV [97]; this may suggest that impairment of CMI alone may contribute to the development of severe eczema herpeticum. Similar to humoral immunity impairment in asthmatics, the development of CMI may be impaired by the decreased response to epitopes or pathogenspecific rapid waning of the immunity.

\section{Possible Pathogenic Relationship between Asthma and COVID-19}

Mast cells are at the center of asthma pathogenesis especially Th2 type; similarly, they also play a significant role in the 
TABLE 1: Studies that evaluated the benefits of corticosteroids in COVID-19 patients.

\begin{tabular}{lcc}
\hline Study, year & Aspect studied & Major findings \\
\hline The inhibitory effects of LAMA glycopyrronium, & $\begin{array}{c}\text { Glycopyronium, formoterol, and a combination of } \\
\text { glycopyrronium, formoterol, and budesonide } \\
\text { inhibit HCoV-229E replication partly by inhibiting } \\
\text { receptor expression and/or endosomal function and } \\
\text { that these drugs modulate infection-induced } \\
\text { inflammation in the airway }\end{array}$ \\
\hline
\end{tabular}

Intravenous dexamethasone plus standard care,

To determine whether intravenous dexamethasone compared with standard of care alone, resulted in a

Tomazini et al., 2020 [84] increases the number of ventilator-free days among statistically significant increase in the number of patients with COVID-19-associated ARDS days alive and free of mechanical ventilation over 28 days ( 6.6 days vs 4.0 days)

In this Bayesian randomized clinical trial that included 403 patients and was stopped early after results from another trial were released, treatment

The Writing Committee for the REMAP-CAP Investigators, 2020 [85]

To determine whether hydrocortisone improves outcome for patients with severe COVID-19 with a 7-day fixed-dose course of hydrocortisone or

shock-dependent dosing of hydrocortisone, compared with no hydrocortisone, resulted in $93 \%$ and $80 \%$ probabilities of superiority, respectively, with regard to the odds of improvement in organ support-free days within 21 days

$22.9 \%$ and $25.7 \%$ of patients in the dexamethasone group and usual treatment group, respectively, died within 28 days (adjusted odd rate ratio, $0.83 ; 95 \%$ CI [0.75-0.93], $P<0.001)$

The RECOVERY Collaborative To evaluate the effects of oral or intravenous Group, 2020 [86]
To assess if inhaled glucocorticoids would be an Ramakrishnan et al., 2021 [88] effective treatment for COVID-19 patients within 7 days of onset of mild symptoms
Therefore, the use of dexamethasone resulted in lower 28-day mortality among those who were receiving either invasive mechanical ventilation or oxygen alone at randomization but not among those receiving no respiratory support

$14 \%$ and $1 \%$ in the usual group and budesonide group, respectively, experienced primary outcomes

(difference on proportion, $0.131,95 \% \mathrm{CI}$ [0.043-0.218], $P=0.004$ )

Therefore, early administration of inhaled budesonide reduced the likelihood of needing urgent medical care and reduced time to recovery after early COVID-19. pathogenesis of SARS-CoV-2, especially in inducing and sustaining inflammation [30, 98-100]. In addition, other inflammatory cells such as macrophages, basophil, and T lymphocytes play essential roles in both diseases; however, their respective contribution in poorly controlled asthmatics infected with SARS-CoV-2 may be limited. Therefore, it is logical to overview individual pathogenesis and analyze the possible ways the SARS-CoV-2 infection contributes to asthma exacerbation.

6.1. Overview of Asthma Pathogenesis. Asthma's pathogenesis is mediated by deranged response to common allergens by eliciting an exuberant inflammatory response and its subsequent effect in lung parenchymal tissues, specifically the airway smooth muscles. Therefore, airway hyper-responsiveness is accompanied by enhanced sensory irritability of the airways and increased mucus secretion.

Dendritic cells process the inhaled allergen and migrate to local lymphoid collections, and through MHC class II, antigen presentation occurs. Depending on dendritic cells' potency to synthesize IL-12, the balance between Th1 and Th2 responses is realized by favoring the Th1 response [101]. Several studies have shown that Th1 responses become more apparent with asthma severity [102-104]. Thus, the Th1/Th2 imbalance may explain the tissue-damaging aspects of severe asthma. In addition, Th1 cells and CD8+ cells have also been implicated in asthma exacerbation, especially following viral infection; however, the exact mechanism is still debatable $[105,106]$. Therefore, asthma's pathogenesis is generally driven by variable Th1/Th2 cellular responses [107].

Mast cells have long been associated with asthma, with early asthmatic reaction following allergen inhalation being mast cell-dependent. Drugs such as sodium cromoglycate and nedocromil sodium inhibit mast cell degranulation, further strengthening the association with asthma [108]. After sensitization by an allergen, Th2 promotes IgE production specific to that allergen and is eventually taken up by mast cells, which becomes the basis of initial allergic reaction in asthmatics [109]. Mast cells in the airway epithelium and 
submucosa are important in immediate allergic reactions such as bronchoconstriction and increased mucus secretion. In contrast, mast cells located deeper in the airway wall play an essential role in chronic inflammatory responses in asthmatics [98, 110, 111]. In chronic asthmatics, mast cell concentration is significantly increased in association with airway smooth muscle (ASM) in large and small airways [111]. At this site, mast cells interact with ASM through autacoid mediators that can induce fibrogenesis, hyperplasia, and hypertrophy of smooth muscles as part of remodeling response. This phase of cytokine secretion constitutes the late-phase postallergen sensitization. It comprises the recruitment of inflammatory cells that mainly participate in chronic inflammation such as eosinophils, basophils, neutrophils, and $T$ helper and memory $T$ cells to the allergen site. Monocytes and dendritic cells can also be recruited $[112,113]$.

6.2. Overview of COVID-19 Pathogenesis. Type II pneumocytes are the primary type of cells implicated in the pathogenesis of COVID-19. Furthermore, other cells with angiotensin convert enzyme-2 (ACE2) receptors, such as those located in the vascular epithelial and endothelial cells, cardiomyocytes, intestinal epithelia cells, renal epithelial cells, and proximal renal cells, can also be infected [114]. ACE2 mRNA expression is also high in the cerebral cortex, hypothalamus, striatum, and brainstem. Hence, this can explain symptoms such as anosmia and dysgeusia $[115,116]$. The host's immune system is activated as a result ofpathogen antigens such as pathogenassociated molecular patterns (PAMPs) and as an injury or damage-associated molecular patterns (DAMPs) following SARS-CoV-2 infection of the susceptible cells [117-120]. DAMPs and PAMPs are recognized by neighboring cells such as epithelial cells, endothelial cells, and macrophages, leading to proinflammatory cytokines such as IL-6, interferon-gamma-induced protein 10 (IP$10)$, and macrophage inflammatory protein. These mediators attract monocytes, neutrophils, macrophages, and $T$ cells at the infection site aggravating the inflammation [121]. These mediators are indicators of Th1 response similar to SARS-CoV-1 and MERS-CoV [122].

However, mast cells are also a key component of proinflammatory cytokines in COVID-19 because of infection from SARS-CoV-2 [112, 123-125]. Various viral components can activate mast cells through toll-like receptor type 3 , which can recognize PAMP with an outcome of inducing cytokine production. Additionally, mast cells possess a significant amount of ACE2 receptors required for the binding of SARS-CoV-2 [99, 126]. Furthermore, following stimulation, mast cells rapidly secrete preformed granules-stored inflammatory mediators such as histamine, TNF- $\alpha$, prostaglandin $\mathrm{D}_{2}$ $\left(\mathrm{PGD}_{2}\right)$, and several other chemokines [127]. Acute inflammatory mediators are released immediately, while delayed inflammatory mediators are released progressively within 6 to 24 hours. Besides the contribution of type II pneumocytes in developing cytokine-storm, several studies have emphasized the importance of mast cells as an essential contributor to the pathology $[30,31,99,100]$.

\subsection{The Implication of COVID-19 Pathogenesis in Asthmatics.} One of the common routes of inflammation in COVID-19 and asthma, mainly if asthma is poorly controlled, is the activation of Th1 cells. In asthmatics, Th1 has a significant contribution in maintaining inflammation in the epithelial and subepithelial layers of the airway leading to swelling of the bronchial wall, increased nonspecific airway hyper-responsiveness, chronic state of inflammation, and sustained airway remodeling $[98,128,129]$. The activation of mast cells by SARS-CoV-2 infection can worsen asthma control in several ways. Mast cell-derived mediators, mainly histamine, leukotrienes, $\mathrm{PGD}_{2}, \mathrm{PGE}_{2}$, tumor necrosis factor (TNF), thymic stromal lymphopoietin (TSL), and tryptase, induce the classic features of early asthmatic reaction in vivo, therefore inducing bronchoconstriction, mucosal edema, and mucus hypersecretion and hence the observed worsening of asthma control in a subset of asthmatics infected with SARS-CoV-2 [128, 130, 131].

\section{COVID-19 Incidences in Asthmatics}

There is a significant regional variation on the prevalence of symptomatic COVID-19 asthmatic patients. In one of the earlier studies that assessed 140 hospitalized COVID-19 patients in Wuhan, China, no asthma cases were observed [132]. Another multicenter study included 476 patients and studied those patients' clinical characteristics; none of the patients were asthmatic [133]. In another systematic review of the prevalence of comorbidities in patients with COVID19 in China, the prevalence of asthma among admitted patients was $1.5 \%$ [134]. Similar results were observed in Italy, whereby the prevalence of asthma among 1591 patients was very low such that it was difficult to assess if it was a significant risk factor.

A large national cross-sectional study conducted in China in 2019 concluded that asthma is significantly underdiagnosed and undertreated [135], with only $28 \%$ of asthmatics reporting to be diagnosed by a physician. Therefore, this may create a considerable bias in identifying risk factors for COVID-19, as the clinical presentation of COVID-19 may mask the clinical features of asthma in a previously undiagnosed patient. Furthermore, studies for Australia, Italy, and the United States have reported relatively different clinical features and functional characteristics [136-138]. Furthermore, it is common to find a varied degree of irreversible airway obstruction in the elderly population, complicating the diagnosis [139].

In contrast to China and Italy, asthma was a significant risk factor for morbidity and mortality of COVID-19 in other studies done in the United States and the United Kingdom. More than $9 \%$ of 5,700 hospitalized patients were asthmatic in one observational study in New York [140]. The prevalence in 16,749 admitted COVID-19 patients in the UK is even higher at $14 \%$. Studies that assessed the asthmatic 
proportion that know their diagnosis in these countries are few. These critical observations may show that most asthmatics in these countries know their diagnosis and strengthen the known fact that asthma is a risk factor of pneumonia.

In another large-scale nationwide study with a cohort of 7340 COVID-19 patients, severe outcomes were observed in $6.9 \%$ and $3.7 \%$ of patients with and without asthma, respectively (adjusted $\mathrm{OR}=1.62$ ), and 4.7 and 3.7 of patients with and without allergic rhinitis, respectively (adjusted $\mathrm{OR}=1.27 ; P<0.05)$. Furthermore, individuals with nonallergic asthma had a higher risk of severe outcomes from COVID-19 than those with allergic asthma in the study [141, 142].

The inconsistent findings between asthma and the severity of COVID-19 may be because of patients' age, disease severity disparity, disease control disparity, racial disparities, differing criteria for hospitalization, and scale of study. In addition, few studies have reported adequate clinical information in asthmatics with COVID-19, such as lung function, control status, asthma phenotypes, and treatment regimen; therefore, in this scenario, comparing different studies becomes difficult.

\section{Clinical Presentation of COVID- 19 in Asthmatics}

Although both asthma and COVID-19 are primarily diseases of the respiratory system, their respective clinical features can vary significantly; however, logically, in an asthmatic patient with exacerbation presenting with COVID-19, clinically, we expect to get a varied combination of clinical features contributed by the two diseases.

Clinical presentation of acute asthma exacerbation varies considerably, from mild form to dramatic presentation of acute severe asthma exacerbation (status asthmaticus), and the severity of the episode may change abruptly even during treatment [143]. Nevertheless, the symptomatology is quite similar with respect to the severity of the disease with episodes and extent of exacerbation presenting with various degrees of exaggeration of symptoms. The four most common symptoms in asthmatics are wheeze, cough, shortness of breath or difficulty breathing, and varied sensation of chest tightness [144]. On physical examination, high-pitched, musical wheezes are vital signs though not specific in asthmatics. Lower-pitched rhonchi could be heard in some patients during auscultation if wheezes were absent [143]. Additionally, crackles may also be heard during physical examination [145].

COVID-19 has a wide range of symptoms; however, the commonest symptoms are cough, usually dry, headache, fever, and myalgias. In addition, dyspnea, sore throat, diarrhea, nausea and vomiting, and loss of smell or taste are also frequently encountered in these patients [146]. A study that analyzed the characteristics of pulmonary auscultation in patients with laboratory-confirmed COVID-19 found that $73.7 \%$ of patients cough during auscultation; furthermore, using high-quality auscultation recordings, wheezes, and coarse crackles were the commonest findings [147]. Additionally, most cases had normal breath sounds in the upper lungs. However, the incidences of abnormal breath sounds were more prevalent toward the lung bases, especially the posterior of the chest.

The pathophysiology of respiratory failure in asthma and COVID-19 are quite different. In asthma, the main aspects are respiratory flow limitation, which is generally due to inflammation and bronchospasm; however, in COVID-19, vascular microthrombi, shunts, and alveolar exudate predominate [148-152]. Moreover, during mechanical ventilation, the pathophysiology of the underline disease process is thought to be heterogeneous. However, expiratory flow limitation is not commonly observed unless the patient has a concurrent obstructive pulmonary disease [153].

These clinical characteristics do not exclude the possibility of having COVID-19-related bilateral pneumonia in addition to an asthmatic exacerbation; therefore, we advise that both conditions, asthma and COVID-19, should be managed accordingly.

\section{Conclusion and Recommendations}

It is estimated that more than $60 \%$ of all asthmatics are poorly controlled and, therefore, at increased risk of acquiring lower respiratory infections that may further worsen the disease control. At the time when the world is faced with a respiratory virus with mortality several times as that of seasonal flu, we advise clinicians to try to achieve adequate disease control in asthmatic patients who are inadequately controlled. Moreover, asthmatics with COVID-19 may present with asthma exacerbations; hence, it is essential to perform a thorough clinical assessment in these patients and manage them accordingly. These approaches may prove vital in reducing morbidity and mortality in this population. However, further studies with a higher level of evidence are needed to elucidate the association between COVID-19 and asthma control, especially their respective contribution to morbidity and mortality.

\section{Conflicts of Interest}

The authors declare that there are no conflicts of interest regarding the publication of this article.

\section{References}

[1] I. Koivula, M. Sten, and P. H. Makela, "Risk factors for pneumonia in the elderly," The American Journal of Medicine, vol. 96, no. 4, pp. 313-320, 1994.

[2] Y. Vinogradova, J. Hippisley-Cox, and C. Coupland, "Identification of new risk factors for pneumonia: population-based case-control study," British Journal of General Practice, vol. 59, no. 567, pp. e329-e338, 2009.

[3] B. M. Farr, M. A. Woodhead, J. T. Macfarlane et al., "Risk factors for community-acquired pneumonia diagnosed by general practitioners in the community," Respiratory Medicine, vol. 94, no. 5, pp. 422-427, 2000.

[4] B. M. Farr, C. L. R. Bartlett, J. Wadsworth, and D. L. Miller, "Risk factors for community-acquired pneumonia diagnosed upon hospital admission," Respiratory Medicine, vol. 94, no. 10, pp. 954-963, 2000. 
[5] S. Jain, "Epidemiology of viral pneumonia," Clinics in Chest Medicine, vol. 38, no. 1, pp. 1-9, 2017.

[6] S. B. Greenberg, "Viral pneumonia," Infectious Disease Clinics of North America, vol. 5, no. 3, pp. 603-621, 1991.

[7] E. K. Miller, K. M. Edwards, G. A. Weinberg et al., "A novel group of rhinoviruses is associated with asthma hospitalizations," The Journal of Allergy and Clinical Immunology, vol. 123, no. 1, pp. 98-104, 2009.

[8] D. Dandachi and M. C. Rodriguez-Barradas, "Viral pneumonia: etiologies and treatment," Journal of Investigative Medicine, vol. 66, no. 6, pp. 957-965, 2018.

[9] P. A. B. Wark, S. L. Johnston, F. Bucchieri et al., "Asthmatic bronchial epithelial cells have a deficient innate immune response to infection with rhinovirus," Journal of Experimental Medicine, vol. 201, no. 6, pp. 937-947, 2005.

[10] B. N. Lambrecht and H. Hammad, "The immunology of asthma," Nature Immunology, vol. 16, no. 1, pp. 45-56, 2015.

[11] P. G. Holt, D. H. Strickland, B. J. Hales, and P. D. Sly, "Defective respiratory tract immune surveillance in asthma," Chest, vol. 145, no. 2, pp. 370-378, 2014.

[12] P. G. Holt and P. D. Sly, "Viral infections and atopy in asthma pathogenesis: new rationales for asthma prevention and treatment," Nature Medicine, vol. 18, no. 5, pp. 726-735, 2012.

[13] Y. J. Juhn, "Risks for infection in patients with asthma (or other atopic conditions): is asthma more than a chronic airway disease?" The Journal of Allergy and Clinical Immunology, vol. 134, no. 2, pp. 247-257, 2014.

[14] J. A. Castro-Rodriguez, K. Abarca, and E. Forno, "Asthma and the risk of invasive pneumococcal disease: a metaanalysis," Pediatrics, vol. 145, no. 1, Article ID e20191200, 2020.

[15] S. Pedersen, "From asthma severity to control: a shift in clinical practice," Primary Care Respiratory Journal, vol. 19, no. 1, pp. 3-9, 2010.

[16] H. K. Reddel, E. D. Bateman, A. Becker et al., "A summary of the new GINA strategy: a roadmap to asthma control," European Respiratory Journal, vol. 46, no. 3, pp. 622-639, 2015.

[17] WHO, Chronic Respiratory Diseases: Asthma, WHO, Geneva, Switzerland, 2021, https://www.who.int/news-room/qa-detail/chronic-respiratory-diseases-asthma.

[18] T. Vos, A. D. Flaxman, M. Naghavi et al., "Years lived with disability (YLDs) for 1160 sequelae of 289 diseases and injuries 1990-2010: a systematic analysis for the Global Burden of Disease Study 2010," The Lancet (North American Edition), vol. 380, no. 9859, pp. 2163-2196, 2012.

[19] R. Lozano, M. Naghavi, K. Foreman et al., "Global and regional mortality from 235 causes of death for 20 age groups in 1990 and 2010: a systematic analysis for the Global Burden of Disease Study 2010," The Lancet (North American Edition), vol. 380, no. 9859, pp. 2095-2128, 2012.

[20] B. J. Sheares, "Recurrent pneumonia in children," Pediatric Annals, vol. 31, no. 2, pp. 109-114, 2002.

[21] G. Cabezuelo Huerta, S. Vidal Micó, A. Abeledo Gómez, and P. Frontera Izquierdo, "Causas subyacentes de neumonía recurrente," Anales de Pediatría, vol. 63, no. 5, pp. 409-412, 2005.

[22] R. Lichenstein, A. H. Suggs, and J. Campbell, "Pediatric pneumonia," Emergency Medicine Clinics of North America, vol. 21, no. 2, pp. 437-451, 2003.

[23] R. R. Wittler, "Persistent and recurrent pneumonia," in Principles and Practice of Pediatric Infectious Diseases, pp. 250-257, Elsevier, Amsterdam, Netherlands, 2018.
[24] WHO, Naming The Coronavirus Disease (COVID-19) and The Virus That Causes It, WHO, Geneva, Switzerland, 2021, https://www.who.int/emergencies/diseases/novelcoronavirus-2019/technical-guidance/naming-thecoronavirus-disease-(covid-2019)-and-the-virus-thatcauses-it.

[25] D. Cucinotta and M. Vanelli, "WHO declares COVID-19 a pandemic," Acta Bio-Medica: Atenei Parmensis, vol. 91, no. 1, pp. 157-160, 2020.

[26] A. Spinelli and G. Pellino, "COVID-19 pandemic: perspectives on an unfolding crisis," British Journal of Surgery, vol. 107, no. 7, pp. 785-787, 2020.

[27] K. L. Bajema, A. M. Oster, O. L McGovern et al., "Persons evaluated for 2019 novel coronavirus - United States, January 2020," MMWR. Morbidity and mortality weekly report, vol. 69, no. 6, pp. 166-170, 2020.

[28] D. Wang, B. Hu, C. Hu et al., "Clinical characteristics of 138 hospitalized patients with 2019 novel coronavirus-infected pneumonia in wuhan, China," Journal of the American Medical Association, vol. 323, no. 11, p. 1061, 2020 Published online February 2020.

[29] J. F.-W. Chan, S. Yuan, K.-H. Kok et al., "A familial cluster of pneumonia associated with the 2019 novel coronavirus indicating person-to-person transmission: a study of a family cluster," The Lancet, vol. 395, no. 10223, pp. 514-523, 2020.

[30] L. B. Afrin, L. B. Weinstock, and G. J. Molderings, "Covid-19 hyperinflammation and post-Covid-19 illness may be rooted in mast cell activation syndrome," International Journal of Infectious Diseases, vol. 100, pp. 327-332, 2020.

[31] B. Hu, S. Huang, and L. Yin, "The cytokine storm and COVID-19," Journal of Medical Virology, vol. 93, no. 1, pp. 250-256, 2021.

[32] R. E. Jordan, P. Adab, and K. K. Cheng, "Covid-19: risk factors for severe disease and death,” BMJ, vol. 368, Article ID $\mathrm{m} 1198,2020$.

[33] M. J. Cummings and M. R. O'Donnell, "Study of critically ill patients with COVID-19 in New York City-authors' reply," The Lancet, vol. 396, no. 10257, p. 1064, 2020.

[34] C. I. Bloom, T. M. Drake, A. B. Docherty et al., "Risk of adverse outcomes in patients with underlying respiratory conditions admitted to hospital with COVID-19: a national, multicentre prospective cohort study using the ISARIC WHO Clinical Characterisation Protocol UK," The Lancet Respiratory Medicine, vol. 9, 2021.

[35] Global Initiative for Asthma, Global Initiative for Asthma, GINA, Fontana-on-Geneva Lake, WI, USA, 2021, https:// ginasthma.org/.

[36] M. Masoli, D. Fabian, S. Holt, and R. Beasley, "The global burden of asthma: executive summary of the GINA Dissemination Committee report," Allergy, vol. 59, no. 5, pp. 469-478, 2004.

[37] M. Daya, N. Rafaels, T. M. Brunetti et al., "Association study in African-admixed populations across the Americas recapitulates asthma risk loci in non-African populations," Nature Communications, vol. 10, no. 1, p. 880, 2019.

[38] D. Adeloye, K. Y. Chan, I. Rudan, and H. Campbell, "An estimate of asthma prevalence in Africa: a systematic analysis," Croatian Medical Journal, vol. 54, no. 6, pp. 519-531, 2013.

[39] C. K. W. Lai, T. S. de Guia, Y.-Y. Kim et al., "Asthma control in the Asia-Pacific region: the asthma insights and reality in Asia-Pacific study," The Journal of Allergy and Clinical Immunology, vol. 111, no. 2, pp. 263-268, 2003. 
[40] S. P. Peters, G. Ferguson, Y. Deniz, and C. Reisner, "Uncontrolled asthma: a review of the prevalence, disease burden and options for treatment," Respiratory Medicine, vol. 100, no. 7, pp. 1139-1151, 2006.

[41] H. S. Zahran, C. M. Bailey, X. Qin, and J. E. Moorman, "Assessing asthma control and associated risk factors among persons with current asthma-findings from the child and adult Asthma Call-back Survey," Journal of Asthma, vol. 52, no. 3, pp. 318-326, 2015.

[42] P. Goyal, J. J. Choi, L. C. Pinheiro et al., "Clinical characteristics of covid-19 in New York city," New England Journal of Medicine, vol. 382, no. 24, pp. 2372-2374, 2020.

[43] Canadian paediatric society, Paediatric Asthma and COVID19, Canadian paediatric society, Ottawa, Canada, 2021, https://www.cps.ca/en/documents/position/paediatricasthma-and-covid-19 Accessed June 24.

[44] L. M. Graham and N. Eid, "The impact of asthma exacerbations and preventive strategies," Current Medical Research and Opinion, vol. 31, no. 4, pp. 825-835, 2015.

[45] M. R. Sears, "Epidemiology of asthma exacerbations," The Journal of Allergy and Clinical Immunology, vol. 122, no. 4, pp. 662-668, 2008.

[46] E. Forno and J. C. Celedón, "Predicting asthma exacerbations in children," Current Opinion in Pulmonary Medicine, vol. 18, no. 1, pp. 63-69, 2012.

[47] J. R. Castillo, S. P. Peters, and W. W. Busse, "Asthma exacerbations: pathogenesis, prevention, and treatment," The Journal of Allergy and Clinical Immunology: In Practice, vol. 5, no. 4, pp. 918-927, 2017.

[48] H. K. Reddel, D. R. Taylor, E. D. Bateman et al., "An official American thoracic society/European respiratory society statement: asthma control and exacerbations," American Journal of Respiratory and Critical Care Medicine, vol. 180, no. 1, pp. 59-99, 2009.

[49] L. Cazzoletti, A. Marcon, C. Janson et al., "Asthma control in Europe: a real-world evaluation based on an international population-based study," The Journal of Allergy and Clinical Immunology, vol. 120, no. 6, pp. 1360-1367, 2007.

[50] H. S. Zahran, C. M. Bailey, X. Qin, and J. E. Moorman, "Assessing asthma severity among children and adults with current asthma," Journal of Asthma, vol. 51, no. 6, pp. 610-617, 2014.

[51] H. J. Zar and M. E. Levin, "Challenges in treating pediatric asthma in developing countries," Pediatric Drugs, vol. 14, no. 6, pp. 353-359, 2012.

[52] K. F. Rabe, P. A. Vermeire, J. B. Soriano, and W. C. Maier, "Clinical management of asthma in 1999: the asthma insights and reality in Europe (AIRE) study," European Respiratory Journal, vol. 16, no. 5, pp. 802-807, 2000, http://erj. ersjournals.com/content/16/5/802.abstract.

[53] J. M. Ramsahai, P. M. Hansbro, and P. A. B. Wark, "Mechanisms and management of asthma exacerbations," American Journal of Respiratory and Critical Care Medicine, vol. 199, no. 4, pp. 423-432, 2019.

[54] P. A. B. Wark, S. L. Johnston, I. Moric, J. L. Simpson, M. J. Hensley, and P. G. Gibson, "Neutrophil degranulation and cell lysis is associated with clinical severity in virusinduced asthma," European Respiratory Journal, vol. 19, no. 1, pp. $68-75,2002$.

[55] S. L. Johnston, P. K. Pattemore, G. Sanderson et al., "Community study of role of viral infections in exacerbations of asthma in 9-11 year old children," BMJ, vol. 310, no. 6989, pp. 1225-1229, 1995.
[56] S. D. Message, V. Laza-Stanca, P. Mallia et al., "Rhinovirusinduced lower respiratory illness is increased in asthma and related to virus load and Th1/2 cytokine and IL-10 production," Proceedings of the National Academy of Sciences, vol. 105, no. 36, pp. 13562-13567, 2008.

[57] N. G. Papadopoulos, A. Papi, S. Psarras, and S. L. Johnston, "Mechanisms of rhinovirus-induced asthma," Paediatric Respiratory Reviews, vol. 5, no. 3, pp. 255-260, 2004.

[58] S. L. Friedlander and W. W. Busse, "The role of rhinovirus in asthma exacerbations," The Journal of Allergy and Clinical Immunology, vol. 116, no. 2, pp. 267-273, 2005.

[59] P. J. Barnes and I. M. Adcock, "How do corticosteroids work in asthma?" Annals of Internal Medicine, vol. 139, no. 5 Part_1, pp. 359-370, 2003.

[60] I. K. Taylor and R. J. Shaw, "The mechanism of action of corticosteroids in asthma," Respiratory Medicine, vol. 87, no. 4, pp. 261-277, 1993.

[61] G. Rachelefsky, "Inhaled corticosteroids and asthma control in children: assessing impairment and risk," Pediatrics, vol. 123, no. 1, pp. 353-366, 2009.

[62] R. A. Pauwels, C.-G. Löfdahl, D. S. Postma et al., "Effect of inhaled formoterol and budesonide on exacerbations of asthma," New England Journal of Medicine, vol. 337, no. 20, pp. 1405-1411, 1997.

[63] L. Lasmar, P. Camargos, N. S. Champs et al., "Adherence rate to inhaled corticosteroids and their impact on asthma control," Allergy, vol. 64, no. 5, pp. 784-789, 2009.

[64] C. Lessing, C. Mace, and K. Bissell, "The availability, pricing and affordability of three essential asthma medicines in 52 low-and middle-income countries," PharmacoEconomics, vol. 31, no. 11, pp. 1063-1082, 2013.

[65] G. Crompton, "A brief history of inhaled asthma therapy over the last fifty years," Primary Care Respiratory Journal, vol. 15, no. 6, pp. 326-331, 2006.

[66] J. A. Castro-Rodriguez and G. J. Rodrigo, "The role of inhaled corticosteroids and montelukast in children with mildmoderate asthma: results of a systematic review with metaanalysis," Archives of Disease in Childhood, vol. 95, no. 5, pp. 365-370, 2010.

[67] J. R. Bach, Y. Ishikawa, and H. Kim, "Prevention of pulmonary morbidity for patients with duchenne muscular dystrophy," Chest, vol. 112, no. 4, pp. 1024-1028, 1997.

[68] P. J. Barnes, "Inhaled corticosteroids," Pharmaceuticals, vol. 3, no. 3, pp. 514-540, 2010.

[69] H. Tanaka, F. Hirano, Y. Nomura et al., "Relative glucocorticoid potency revisited," Rheumatology International, vol. 14, no. 1, pp. 9-12, 1994

[70] E. Dubois, "Clinical potencies of glucocorticoids: what do we really measure?" Current Respiratory Medicine Reviews, vol. 1, no. 1, pp. 103-108, 2005.

[71] D. Jaffuel, P. Demoly, C. Gougat et al., "Transcriptional potencies of inhaled glucocorticoids," American Journal of Respiratory and Critical Care Medicine, vol. 162, no. 1, pp. 57-63, 2000.

[72] M. Noonan, P. Chervinsky, W. W. Busse et al., "Fluticasone propionate reduces oral prednisone use while it improves asthma control and quality of life," American Journal of Respiratory and Critical Care Medicine, vol. 152, no. 5, pp. 1467-1473, 1995.

[73] M. Masoli, M. Weatherall, S. Holt, and R. Beasley, "Moderate dose inhaled corticosteroids plus salmeterol versus higher doses of inhaled corticosteroids in symptomatic asthma," Thorax, vol. 60, no. 9, pp. 730-734, 2005. 
[74] C. E. Rodriguez-Martinez, M. P. Sossa-Briceño, and J. A. Castro-Rodriguez, "Advantage of inhaled corticosteroids as additional therapy to systemic corticosteroids for pediatric acute asthma exacerbations: a cost-effectiveness analysis," Journal of Asthma, vol. 57, no. 9, pp. 949-958, 2020.

[75] M. Yang, H. Chen, Y. Zhang et al., "Long-term use of inhaled corticosteroids and risk of upper respiratory tract infection in chronic obstructive pulmonary disease: a meta-analysis," Inhalation Toxicology, vol. 29, no. 5, pp. 219-226, 2017.

[76] M. Yang, Y. Zhang, H. Chen, J. Lin, J. Zeng, and Z. Xu, "Inhaled corticosteroids and risk of upper respiratory tract infection in patients with asthma: a meta-analysis," Infection, vol. 47, no. 3, pp. 377-385, 2019.

[77] I. A. Yang, M. S. Clarke, E. H. Sim, and K. M. Fong, "Inhaled corticosteroids for stable chronic obstructive pulmonary disease," Cochrane Database of Systematic Reviews, vol. 7, 2012.

[78] A. Singanayagam, N. Glanville, J. L. Girkin et al., "Corticosteroid suppression of antiviral immunity increases bacterial loads and mucus production in COPD exacerbations," Nature Communications, vol. 9, no. 1, p. 2229, 2018.

[79] J. M. Davies, M. L. Carroll, H. Li et al., "Budesonide and formoterol reduce early innate anti-viral immune responses in vitro," PLoS One, vol. 6, no. 11, Article ID e27898, 2011.

[80] J. L. Simpson, M. Carroll, I. A. Yang et al., "Reduced antiviral interferon production in poorly controlled asthma is associated with neutrophilic inflammation and high-dose inhaled corticosteroids," Chest, vol. 149, no. 3, pp. 704-713, 2016.

[81] P. M. O’Byrne, S. Pedersen, L.-G. Carlsson et al., "Risks of pneumonia in patients with asthma taking inhaled corticosteroids," American Journal of Respiratory and Critical Care Medicine, vol. 183, no. 5, pp. 589-595, 2011.

[82] T. Southworth, C. Pattwell, N. Khan et al., "Increased type 2 inflammation post rhinovirus infection in patients with moderate asthma," Cytokine, vol. 125, Article ID 154857, 2020.

[83] M. Yamaya, H. Nishimura, X. Deng et al., "Inhibitory effects of glycopyrronium, formoterol, and budesonide on coronavirus HCoV-229E replication and cytokine production by primary cultures of human nasal and tracheal epithelial cells," Respiratory Investigation, vol. 58, no. 3, pp. 155-168, 2020.

[84] B. M. Tomazini, I. S. Maia, A. B. Cavalcanti et al., "Effect of dexamethasone on days alive and ventilator-free in patients with moderate or severe acute respiratory distress syndrome and COVID-19," Journal of the American Medical Association, vol. 324, no. 13, pp. 1307-1316, 2020.

[85] R.-C. Investigators TWC for the, "Effect of hydrocortisone on mortality and organ support in patients with severe COVID-19: the REMAP-CAP COVID-19 corticosteroid domain randomized clinical trial," Journal of the American Medical Association, vol. 324, no. 13, pp. 1317-1329, 2020.

[86] Recovery Collaborative Group, P. Horby, W. S. Lim et al., "Dexamethasone in hospitalized patients with covid-19," New England Journal of Medicine, vol. 384, no. 8, pp. 693704, 2020.

[87] UpToDate, COVID-19: Management in Hospitalized Adults-UpToDate, UpToDate, Waltham, MA, USA, 2021, https://www.uptodate.com/contents/covid-19management-in-hospitalized-adults?search=management $\%$ 20of\%20 covid\%2019\&source=search_ result\&selectedTitle $=1 \% 7 \mathrm{E} 150 \&$ usage type $=$ default\&display_rank=1\#H2223242197.
[88] S. Ramakrishnan, D. V. Nicolau, B. Langford et al., "Inhaled budesonide in the treatment of early COVID-19 (STOIC): a phase 2, open-label, randomised controlled trial," The Lancet Respiratory Medicine, vol. 9, 2021.

[89] J. A. Jung, H. Kita, R. Dhillon et al., "Influence of asthma status on serotype-specific pneumococcal antibody levels," Postgraduate Medicine, vol. 122, no. 5, pp. 116-124, 2010.

[90] M. Habibzay, J. I. Saldana, J. Goulding, C. M. Lloyd, and T. Hussell, "Altered regulation of Toll-like receptor responses impairs antibacterial immunity in the allergic lung," Mucosal Immunology, vol. 5, no. 5, pp. 524-534, 2012.

[91] M. Contoli, S. D. Message, V. Laza-Stanca et al., "Role of deficient type III interferon- $\lambda$ production in asthma exacerbations," Nature Medicine, vol. 12, no. 9, pp. 1023-1026, 2006.

[92] C. Beisswenger, K. Kandler, C. Hess et al., "Allergic airway inflammation inhibits pulmonary antibacterial host defense," The Journal of Immunology, vol. 177, no. 3, pp. 1833-1837, 2006.

[93] D. Grove, T. O. Burston, M. L. Wellby, R. M. Ford, and I. J. Forbes, "Humoral and cellular immunity in asthma," The Journal of Allergy and Clinical Immunology, vol. 55, no. 3, pp. 152-163, 1975.

[94] D. I. Grove, J. G. Reid, and I. J. Forbes, "Humoral and cellular immunity in atopic eczema," British Journal of Dermatology, vol. 92, no. 6, pp. 611-618, 1975.

[95] R. Dhillon, B. Yawn, K. Yoo et al., "Impact of asthma on the severity of serious pneumococcal disease," Epidemiology, vol. Suppl 3, 2011.

[96] T. Shirakawa, T. Enomoto, S. Shimazu, and J. M. Hopkin, "The inverse association between tuberculin responses and atopic disorder," Science, vol. 275, no. 5296, pp. 77-79, 1997.

[97] D. Y. M. Leung, P.-S. Gao, D. N. Grigoryev et al., "Human atopic dermatitis complicated by eczema herpeticum is associated with abnormalities in IFN- $\gamma$ response," The Journal of Allergy and Clinical Immunology, vol. 127, no. 4, pp. 965-973, 2011.

[98] P. Bradding, "The role of the mast cell in asthma: a reassessment," Current Opinion in Allergy and Clinical Immunology, vol. 3, no. 1, pp. 45-50, 2003, https://journals.lww. com/co-allergy/Fulltext/2003/02000/The_role_of_the_ mast_cell_in_asthma_a.8.aspx.

[99] T. C. Theoharides, "Potential association of mast cells with coronavirus disease 2019," Annals of Allergy, Asthma, and Immunology, vol. 126, no. 3, pp. 217-218, 2021.

[100] D. Kempuraj, G. P. Selvakumar, M. E. Ahmed et al., "COVID-19, mast cells, cytokine storm, psychological stress, and neuroinflammation," The Neuroscientist, vol. 26, no. 5-6, pp. 402-414, 2020.

[101] H. Kuipers, C. Heirman, D. Hijdra et al., "Dendritic cells retrovirally overexpressing IL-12 induce strong Th1 responses to inhaled antigen in the lung but fail to revert established Th2 sensitization," Journal of Leukocyte Biology, vol. 76, no. 5, pp. 1028-1038, 2004.

[102] J. A. Wisniewski, L. M. Muehling, J. D. Eccles et al., "TH1 signatures are present in the lower airways of children with severe asthma, regardless of allergic status," The Journal of Allergy and Clinical Immunology, vol. 141, no. 6, pp. 20482060, 2018, e13.

[103] E. Truyen, L. Coteur, E. Dilissen et al., "Evaluation of airway inflammation by quantitative Th1/Th2 cytokine mRNA measurement in sputum of asthma patients," Thorax, vol. 61, no. 3, pp. 202-208, 2006. 
[104] M. Gauthier, K. Chakraborty, T. B. Oriss et al., "Severe asthma in humans and mouse model suggests a CXCL10 signature underlies corticosteroid-resistant Th1 bias," JCI insight, vol. 2, no. 13, Article ID e94580, 2017.

[105] A. Hamzaoui, N. Chaouch, H. Graïri, J. Ammar, and K. Hamzaoui, "Inflammatory process of CD8+CD28-T cells in induced sputum from asthmatic patients," Mediators of Inflammation, vol. 2005, no. 3, pp. 160-166, 2005.

[106] S. M. O’Sullivan, "Asthma death, CD8+ T cells, and viruses," Proceedings of the American Thoracic Society, vol. 2, no. 2, pp. 162-165, 2005.

[107] T. Heaton, J. Rowe, S. Turner et al., "An immunoepidemiological approach to asthma: identification of in-vitro $T$ cell response patterns associated with different wheezing phenotypes in children," The Lancet, vol. 365, no. 9454, pp. 142-149, 2005.

[108] S. T. Holgate, "The immunopharmacology of mild asthma约衫 $\star$, The Journal of Allergy and Clinical Immunology, vol. 98, no. 5, Part 2, pp. S7-S16, 1996.

[109] S. J. Galli and M. Tsai, "IgE and mast cells in allergic disease," Nature Medicine, vol. 18, no. 5, pp. 693-704, 2012.

[110] S. Shahana, E. Björnsson, D. Lúdvíksdóttir et al., "Ultrastructure of bronchial biopsies from patients with allergic and non-allergic asthma," Respiratory Medicine, vol. 99, no. 4, pp. 429-443, 2005.

[111] C. E. Brightling, P. Bradding, F. A. Symon, S. T. Holgate, A. J. Wardlaw, and I. D. Pavord, "Mast-cell infiltration of airway smooth muscle in asthma," New England Journal of Medicine, vol. 346, no. 22, pp. 1699-1705, 2002.

[112] A. Olivera, M. A. Beaven, and D. D. Metcalfe, "Mast cells signal their importance in health and disease," The Journal of Allergy and Clinical Immunology, vol. 142, no. 2, pp. 381-393, 2018.

[113] M. C. Liu, W. C. Hubbard, D. Proud et al., "Immediate and late inflammatory responses to ragweed antigen challenge of the peripheral airways in allergic asthmatics: cellular, mediator, and permeability changes," American Review of Respiratory Disease, vol. 144, no. 1, pp. 51-58, 1991.

[114] H. Xu, L. Zhong, J. Deng et al., "High expression of ACE2 receptor of $2019-\mathrm{nCoV}$ on the epithelial cells of oral mucosa," International Journal of Oral Science, vol. 12, no. 1, p. 8, 2020.

[115] A. M. Baig, A. Khaleeq, U. Ali, and H. Syeda, "Evidence of the COVID-19 virus targeting the CNS: tissue distribution, hostvirus interaction, and proposed neurotropic mechanisms," ACS Chemical Neuroscience, vol. 11, no. 7, pp. 995-998, 2020.

[116] N. Kabbani and J. L. Olds, "Does COVID19 infect the brain? If so, smokers might Be at a higher risk," Molecular Pharmacology, vol. 97, no. 5, pp. 351-353, 2020.

[117] J. Thomas, A. Pociute, R. Kevalas, M. Malinauskas, and L. Jankauskaite, "Blood biomarkers differentiating viral versus bacterial pneumonia aetiology: a literature review," Italian Journal of Pediatrics, vol. 46, no. 1, p. 4, 2020.

[118] W. G. Land, "The role of damage-associated molecular patterns in human diseases: Part I - promoting inflammation and immunity," Sultan Qaboos University medical journal, vol. 15, no. 1, pp. e9-e21, 2015.

[119] P. Matzinger, "The danger model: a renewed sense of self," Science, vol. 296, no. 5566, pp. 301-305, 2002.

[120] B. A. Beutler, “TLRs and innate immunity," Blood, vol. 113, no. 7, pp. 1399-1407, 2009.

[121] M. Z. Tay, C. M. Poh, L. Rénia, P. A. MacAry, and L. F. P. Ng, "The trinity of COVID-19: immunity, inflammation and intervention," Nature Reviews Immunology, vol. 20, no. 6, pp. 363-374, 2020.

[122] K.-J. Huang, I.-J. Su, M. Theron et al., "An interferon?-related cytokine storm in SARS patients," Journal of Medical Virology, vol. 75, no. 2, pp. 185-194, 2005.

[123] T. C. Theoharides, "COVID -19 , pulmonary mast cells, cytokine storms, and beneficial actions of luteolin," BioFactors, vol. 46, no. 3, pp. 306-308, 2020.

[124] T. C. Theoharides, P. Valent, and C. Akin, "Mast cells, mastocytosis, and related disorders," New England Journal of Medicine, vol. 373, no. 2, pp. 163-172, 2015.

[125] S. K. Kritas, G. Ronconi, A. Caraffa, C. E. Gallenga, R. Ross, and P. Conti, "Mast cells contribute to coronavirus-induced inflammation: new anti-inflammatory strategy," Journal of Biological Regulators and Homeostatic Agents, vol. 34, no. 1, pp. 9-14, 2020.

[126] P. Conti, A. Caraffa, G. Tete et al., "Mast cells activated by SARS-CoV-2 release histamine which increases IL-1 levels causing cytokine storm and inflammatory reaction in COVID-19," Journal of Biological Regulators and Homeostatic Agents, vol. 34, no. 5, pp. 1629-1632, 2020.

[127] K. Mukai, M. Tsai, H. Saito, and S. J. Galli, "Mast cells as sources of cytokines, chemokines, and growth factors," Immunological Reviews, vol. 282, no. 1, pp. 121-150, 2018.

[128] P. Bradding, A. Walls, and S. Holgate, "The role of the mast cell in the pathophysiology of asthma," The Journal of Allergy and Clinical Immunology, vol. 117, no. 6, pp. 1277-1284, 2006.

[129] S. E. Wenzel, A. A. Fowler, and L. B. Schwartz, "Activation of pulmonary mast cells by bronchoalveolar allergen challenge: in VivoRelease of histamine and tryptase in atopic subjects with and without asthma," American Review of Respiratory Disease, vol. 137, no. 5, pp. 1002-1008, 1988.

[130] E. P. Moiseeva and P. Bradding, "Mast cells in lung inflammation,” Mast Cell Biology, vol. 716, pp. 235-269, 2011.

[131] A. B. Kay, "Allergy and allergic diseases," New England Journal of Medicine, vol. 344, no. 1, pp. 30-37, 2001.

[132] J.-j. Zhang, X. Dong, Y.-y. Cao et al., "Clinical characteristics of 140 patients infected with SARS-CoV-2 in Wuhan, China," Allergy, vol. 75, no. 7, pp. 1730-1741, 2020.

[133] Y. Feng, Y. Ling, T. Bai et al., "COVID-19 with different severities: a multicenter study of clinical features," American Journal of Respiratory and Critical Care Medicine, vol. 201, no. 11, pp. 1380-1388, 2020.

[134] J. Yang, Y. Zheng, X. Gou et al., "Prevalence of comorbidities and its effects in patients infected with SARS-CoV-2: a systematic review and meta-analysis," International Journal of Infectious Diseases, vol. 94, pp. 91-95, 2020.

[135] K. Huang, T. Yang, J. Xu et al., "Prevalence, risk factors, and management of asthma in China: a national cross-sectional study," The Lancet, vol. 394, no. 10196, pp. 407-418, 2019.

[136] A. Gillman and J. A. Douglass, "Asthma in the elderly," Asia Pacific Allergy, vol. 2, no. 2, pp. 101-108, 2012.

[137] R. M. Dunn, P. J. Busse, and M. E. Wechsler, "Asthma in the elderly and late-onset adult asthma," Allergy, vol. 73, no. 2, pp. 284-294, 2018.

[138] S. Battaglia, A. Benfante, M. Spatafora, and N. Scichilone, "Asthma in the elderly: a different disease?" Breathe, vol. 12, no. 1, pp. 18-28, 2016.

[139] K. Lindner, B. Panaszek, and Z. Machaj, "Asthma in the elderly," Polish Archives of Internal Medicine, vol. 117, no. 8, pp. 350-354, 2007.

[140] S. Richardson, J. S. Hirsch, M. Narasimhan et al., "Presenting characteristics, comorbidities, and outcomes among 5700 
patients hospitalized with COVID-19 in the New York city area," Journal of the American Medical Association, vol. 323, no. 20, pp. 2052-2059, 2020.

[141] J. M. Yang, H. Y. Koh, S. Y. Moon et al., "Allergic disorders and susceptibility to and severity of COVID-19: a nationwide cohort study," The Journal of Allergy and Clinical Immunology, vol. 146, no. 4, pp. 790-798, 2020.

[142] Z. Zhu, K. Hasegawa, B. Ma, M. Fujiogi, C. A. Camargo, and L. Liang, "Association of asthma and its genetic predisposition with the risk of severe COVID-19," The Journal of Allergy and Clinical Immunology, vol. 146, no. 2, pp. 327329, 2020, e4.

[143] B. E. Brenner, Emergency Asthma-Barry E. Brenner-Google Books, CRC Press, Boca Raton, FL, USA, Accessed June 27, 2021.

[144] M. O. Patadia, L. L. Murrill, and J. Corey, "Asthma," Otolaryngologic Clinics of North America, vol. 47, no. 1, pp. 23-32, 2014.

[145] P. Mayorga, C. Druzgalski, R. L. Morelos, O. H. González, and J. Vidales, "Acoustics based assessment of respiratory diseases using GMM classification," in Proceedings of the 2010 Annual International Conference of the IEEE Engineering in Medicine and Biology, pp. 6312-6316, Buenos Aires, Argentina, September 2010.

[146] E. K. Stokes, L. D. Zambrano, K. N. Anderson et al., "Coronavirus disease 2019 case surveillance-United States, january 22-May 30, 2020," MMWR. Morbidity and Mortality Weekly Report, vol. 69, no. 24, pp. 759-765, 2020.

[147] B. Wang, Y. Liu, Y. Wang et al., "Characteristics of pulmonary auscultation in patients with 2019 novel coronavirus in China," Respiration, vol. 99, no. 9, pp. 755-763, 2020.

[148] J. T. Olin and M. E. Wechsler, "Asthma: pathogenesis and novel drugs for treatment," BMJ, vol. 349, no. nov24 8, p. g5517, 2014.

[149] S. T. HOLGATE, "Pathogenesis of asthma," Clinical and Experimental Allergy, vol. 38, no. 6, pp. 872-897, 2008.

[150] M. R. Hashan, N. Smoll, C. King et al., "Epidemiology and clinical features of COVID-19 outbreaks in aged care facilities: a systematic review and meta-analysis," EClinicalMedicine, vol. 33, Article ID 100771, 2021.

[151] S. de Bruin, L. D. Bos, M. A. van Roon et al., "Clinical features and prognostic factors in Covid-19: a prospective cohort study," EBioMedicine, vol. 67, Article ID 103378, 2021.

[152] S. H. Puah, B. E. Young, B. E. Young et al., "Clinical features and predictors of severity in COVID-19 patients with critical illness in Singapore," Scientific Reports, vol. 11, no. 1, p. 7477, 2021.

[153] L. Gattinoni, D. Chiumello, P. Caironi et al., "COVID-19 pneumonia: different respiratory treatments for different phenotypes?" Intensive Care Medicine, vol. 46, no. 6, pp. 1099-1102, 2020. 